\title{
IMPAIRED VIBRATORY SENSE IN DIABETES MELLITUS WITH PROTEINURIA
}

\author{
By WILLIAM S. COLLENS, JAMES D. ZILINSKY, LOUIS C. BOAS, AND \\ JEROME J. GREENWALD
}

(From the Medical Services of the Maimonides Hospital, Brooklyn, New York)

(Submitted for publication January 3, 1950; accepted, February 20, 1950)

The use of an electrically activated tuning fork has served as a satisfactory tool for quantitating vibratory sense (1). By this method it was found that diabetics almost invariably revealed an impairment in transmission of vibratory sense impulses (2). It was also observed that the degree of impairment varied widely among these patients. One finding that appeared to be consistently present was that diabetics with renal complications as described by Kimmelstiel and Wilson were the most seriously affected.

Quantitation of vibratory sense was made in 200 diabetics; 100 had proteinuria and the other

\section{PROTEINURIA IN DIABETES}

Vibration Sense Studies

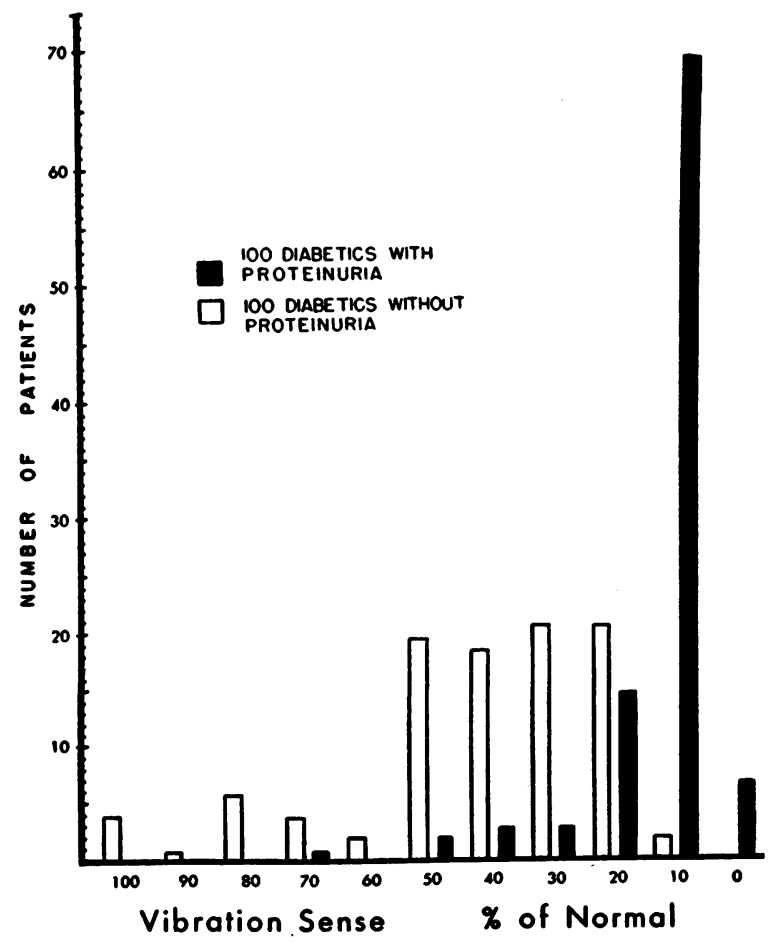

FIG. 1
100 were free from proteinuria. Some of the patients in whom proteinuria was present, also had characteristic retinopathic changes including hemorrhages and exudates, hyaline and granular casts in the urine and evidence of impaired renal function. For the purpose of this study, however, all the patients who had proteinuria, whether or not they had any other features of the KimmelstielWilson syndrome, were placed in one category, the basic denominator for this group of diabetics being the loss of protein through the kidney.

In Figure 1, it will be observed that $76 \%$ of all the diabetics with proteinuria had an impairment

PROTEINURIA IN DIABETES

Age Incidence

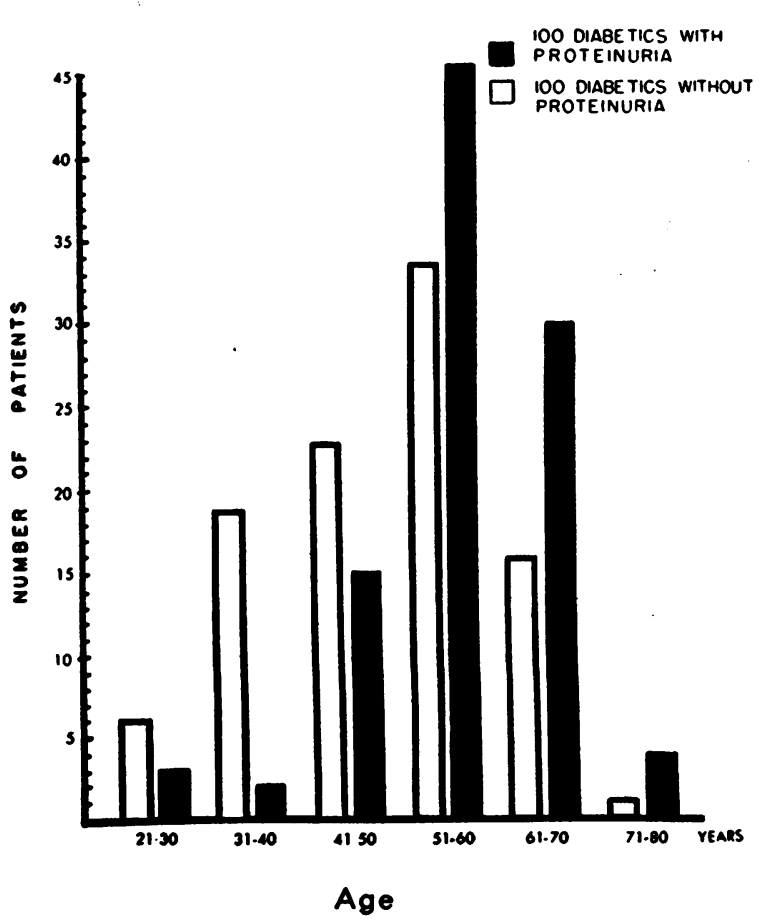

FIG. 2 
PROTEINURIA IN DIABETES
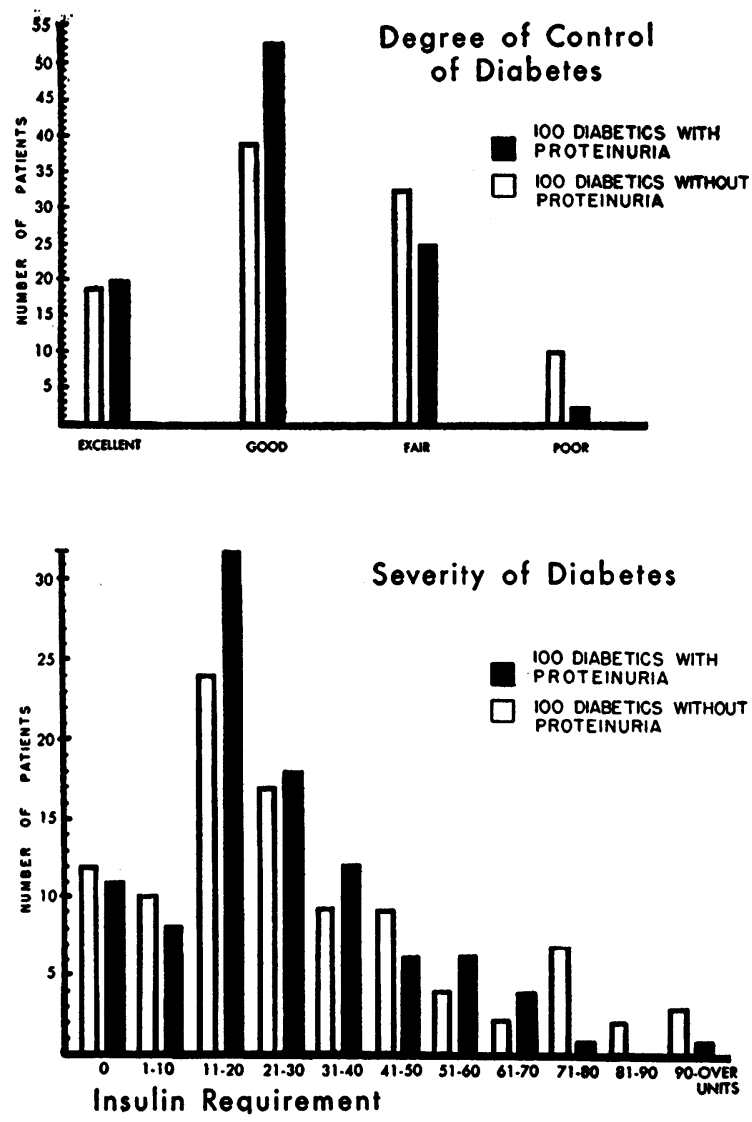

FIG. 3

in vibratory sense worse than $10 \%$ of normal, while only $2 \%$ of the diabetics without proteinuria were as seriously affected. Such contrasting incidence in the two groups makes it apparent that diabetics in whom one or another phase of the Kimmelstiel-Wilson syndrome is developing, have a much more profound impairment in vibratory impulse transmission than the diabetics in whom this complication is not present.

While it is true that most of the patients with proteinuria were over 40 years of age, it still remains that age itself played no part in predetermining the severity of the impairment. This is so because, of the diabetics without proteinuria who were over 40 years of age, only $2 \%$ were as severely affected as the diabetics with proteinuria (see Figure 2).

The severity of the diabetes as determined by the insulin requirements was not materially differ- ent in both groups and thus did not appear to play a part in the differences in severity of impairment of vibratory sense. As a matter of fact, the diabetes appeared to be usually less severe in the patients with proteinuria. Similarly, the degree of control of the diabetes appeared to be about equal in the two groups (see Figure 3).

An analysis of the cases would indicate that the duration of diabetes did not play a part in affecting the severity of impaired vibration sense. While it is true that the patients with proteinuria generally had the disease for a longer period than those without proteinuria, a breakdown of the cases showed that $42 \%$ of the diabetics with proteinuria had the disease over 10 years, compared with $27 \%$ of the cases without proteinuria. Nevertheless, of the $27 \%$ only $2 \%$ were as severely involved as those with proteinuria (see Figure 4).

\section{PROTEINURIA IN DIABETES}

\section{Duration of the Diabetes}

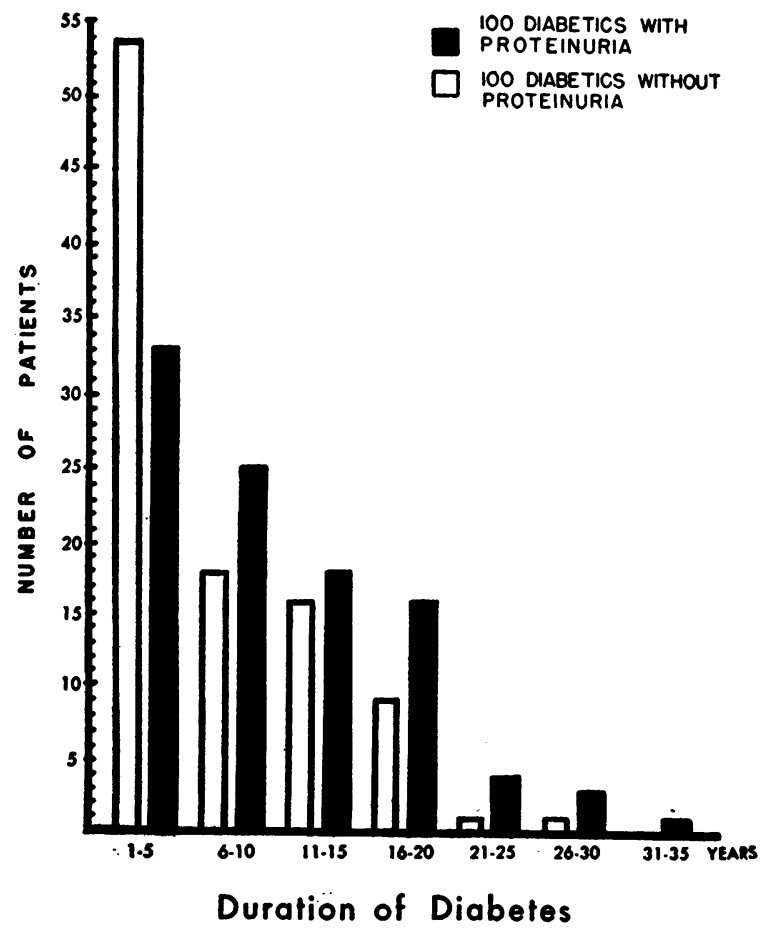

FIG. 4 


\section{DISCUSSION}

It may reasonably be suspected that an impairment in vibratory sense, as determined by the technique described, reflects the status of other impulses passing through peripheral nerves and thus serves to establish the presence of peripheral neuropathy. The interesting coexistence of more advanced neuropathy with proteinuria is the basis for speculating as to whether a kidney through which protein is being lost from the body is also permeable to fractions of vitamin B complex, possessing antineuritic properties. On the other hand one must also ask the question as to whether the condition that makes for a disturbance in the metabolism of the peripheral nerve also makes for increased permeability of the kidney to protein. If the latter is true, then one may suspect a common denominator to be pathogenetically responsible for both proteinuria in diabetes mellitus and peripheral neuropathy.

\section{CONCLUSION}

A study of 100 diabetics with proteinuria showed that they had a much more profound impairment in vibration sense than 100 diabetics without proteinuria.

\section{BIBLIOGRAPHY}

1. Collens, W. S., Zilinsky, J. D., and Boas, L. C., Clinical vibrometer; apparatus to measure vibratory sense quantitatively. Am. J. Med., 1946, 1, 636.

2. Collens, W. S., Zilinsky, J. D., and Boas, L. C., Impaired vibratory sense in diabetes. Am. J. Med., 1946, 1, 638. 